\title{
"Just a wee boy not cut out for prison": Policy and reality in children and young people's journeys through justice in Scotland
}

\section{Deborah Nolan}

Centre for Youth and Criminal Justice, University of Strathclyde, UK

\section{Fiona Dyer}

Centre for Youth and Criminal Justice, University of Strathclyde, UK

\section{Nina Vaswani}

Centre for Youth and Criminal Justice, University of Strathclyde, UK

\begin{abstract}
Youth Justice policy in Scotland, under the 'Whole System Approach' (WSA), progressively espouses maximum diversion, minimum intervention and the use of alternatives to custody wherever possible. Yet Scotland still has one of the highest imprisonment rates in Europe. To explore this discrepancy, this qualitative study used individual interviews and focus groups to document the experiences of 14 young males aged 16 and 17 in one Scottish young offenders' institution on their journeys to custody. Their experiences reveal the significant challenges faced in understanding, navigating, and complying with the justice system, and also indicate that the consistent implementation of WSA is problematic. The disconnection between the intentions of
\end{abstract}


the WSA policy and the practical implementation means that these vulnerable young people are not fully benefiting from the WSA. This paper therefore highlights important gaps between policy, practice and lived experience in youth justice in Scotland.

\section{Keywords}

Youth and criminal justice, Whole System Approach, policy, practice, Scotland

Final Word Count 7,457

\section{Introduction}

With the passage of the Scotland Act 1998 and subsequent devolution, crime control, criminal justice and youth justice are devolved matters which are the responsibility of the Scottish Parliament (McAra, 2008). Scotland has a long-established welfare-based approach to children aged under 18 involved in offending behaviour, with the current policy framework the Whole System Approach (WSA) (Lightowler et al., 2014; Scottish Government, 2015a). At the core of this approach is the recognition that children are not 'mini-adults', either in terms of their development or maturity, and that children involved in offending, especially those who are committing more serious and violent offences, are often extremely vulnerable with multiple, complex needs (McAra and McVie, 2010; National Institute of Mental Health, 2011; Scottish Government, 2014a). As a result, the WSA attempts to provide a holistic approach to addressing needs, vulnerability and deeds, wherever possible with minimal formal intervention and maximum diversion to programming that does not have the trappings of criminal processing, which research 
concludes is the most significant factor in reducing reoffending (Scottish Government, 2015a; Rutherford, 2002; Pitts, 2005; McAra and McVie, 2010).

Where diversion is not possible, the WSA advocates children should be retained in ageappropriate systems, namely the Children's Hearings System (CHS) rather than the adult court (Scottish Government, 2011a). This is because the CHS is the judicial and welfare-based system for young people from birth to age 18, without segregation due to offending behaviour (Lightowler et al., 2014). The CHS has the power to retain young people within the system until their 18th birthday and if they are appearing in court, to give advice to the Judge/Sheriff, which can result in the case being remitted to the CHS for disposal (Criminal Procedure (Scotland) Act 1995).

Similarly under the WSA, opportunities to meet the needs and manage the risks presented by high-risk young people safely and cost effectively in their communities should be maximised, with custody being the last resort, as is consistent with the article 37 of the United Nations Convention on the Rights of the Child (UNCRC) (Scottish Government, 2011a). Moreover, for the critical few young people for whom it is not possible to retain in their communities, secure care should be utilised rather than a young offenders institution (YOI) (Scottish Government, 2011a; Gough, 2016), with the National Association for Youth Justice (NAYJ) having gone as far as to advocate for the abolition of YOls at the earliest opportunity, concluding they are totally unsuited to meet the needs of vulnerable children (Bateman, 2016). While both facilities deprive the child of their liberty, secure care establishments are based on different values to a YOI, providing more relationship-based and therapeutic trauma and attachment informed support, although longitudinal outcome data is scant (Moodie, 2015; Gough, 2016). 
A change in the Scottish Government in 2007 gave rise to a new policy environment and attitudes towards young people involved in offending, marking a significant shift away from more punitive climate that had prevailed in Scotland and elsewhere in the UK in the late 1990s and 2000s. Previous policy had been characterised by the 'responsibilisation' of young people who offend, a focus on 'persistent offenders' and the introduction of the Antisocial Behaviour etc. (Scotland) Act 2004 resulting in rising custody rates and drawing criticism from the UNCRC (Hamilton et al., 2016; Phoenix and Kelly, 2013; Lightowler et al., 2014). This change in tone was crystallised in the WSA, introduced nationally in 2011. Since the mid-late 2000s, the evidence in Scotland suggests that substantial progress has been made in reducing youth offending, which may partially have been influenced by these policy and practice changes (Lightowler et al., 2014; Murray et al., 2015). The number of young people being referred to the CHS on offence grounds, appearing in court, and in YOls has substantially reduced (Lightowler et al., 2014; Scottish Government, 2015a).

In spite of this progress and the clear, evidence-based intentions and rhetoric of WSA policy, various areas of concern and challenges in practice have been identified (Scottish Government, 2017b). In accordance with the UNCRC, children (defined as being under 18 years) in conflict with the law should always be dealt with within the juvenile justice system, with concern repeatedly expressed about children in the UK being tried in adult courts (Harris et al., 2016). In Scotland, Dyer (2016) has highlighted that too many young people aged under 18 continue to be prosecuted as adults in court, being treated as fully responsible for their behaviours and punished as such, bringing lifelong consequences such as criminal records, that can persist into adulthood. Critically, Dyer (2016) concludes that the majority of these young people could have been supported and managed via the CHS. Moreover, while the YOI population has been falling (from 222 at the peak in Scotland in 2008, to an average of 67 in 2016), we still have a sizeable number of young people 
in YOIs, with Scotland continuing to have higher imprisonment rates than most other European countries (Allen and Watson, 2017; Scottish Government, 2015b; Nolan, 2017). As a result, the UNCRC has recently recommended that Scotland should:

Establish the statutory principle that detention should be used as a measure of last resort and for the shortest possible period of time (Harris et al., 2016: 144).

In addition, more young people continue to serve periods of remand and sentence in a YOI rather than in secure care (Gough, 2016; Nolan, 2017; Scottish Government, 2015a). The daily average figures for under 18s in YOls in 2016 were 44 convicted/sentenced and 23 on remand, compared with an average of 10 sentenced in secure care (Nolan, 2017). If the policy environment maximises diversion and the practice setting is broadly congruent, with all 32 of Scotland's Local Authorities signed up to the WSA in principle, then the question remains as to why this phenomenon persists.

This research explores whether the espoused policy intentions of the WSA are being achieved in practice, by documenting the lived experiences and views of young people in a YOI on their journey through the youth and criminal justice system to their eventual arrival in custody. The aim is to highlight areas where implementation appears to be more problematic and the significance of this for young people, to identify factors that may impact on the translation of policy into practice and to make suggestions as to how WSA implementation could be supported further.

Research into the backgrounds of young people involved in offending behaviour and experiences of desistance, as well as direct research with young people in custody, including on their experiences of incarceration, across the UK and further afield is not uncommon (McAra and McVie, 2010; Convery, 2010; Barry, 2016; Terry and Abrams, 2015; Hampson, 2016; Davis et al., 
2013; Deuchar et al., 2016; Broderick and Carnie, 2016; Holligan, 2015). However, while some Scottish research is available, scant attention has been paid to the totality of young people's journeys through the youth and criminal justice system and their experiences of this. Smith et al. (2014) did explore the pathways of young men into and out of custody, as well as their perceptions of this and the support provided on these journeys. This research however relied predominantly on case file analysis, chiefly via standardised prison psychology reports, supplemented by interviews with 11 young men, and was conducted in 2013 when WSA was in its relative infancy. Similarly, research into the implementation or effectiveness of the WSA is limited, with previously completed evaluations having focused on a small number of geographic areas and failed to include the views and experiences of young people (Murray et al., 2015). Therefore, this research will extend the available evidence base.

\section{Method}

Ethical approval was received from the University of Strathclyde Ethics Committee which aims to protect the integrity, security and well-being of participants and researchers in sensitive research settings such as prisons. In addition, the Scottish Prison Service's Research Access and Ethics Committee granted approval.

All 59 males aged under 18 who were resident in the YOI on the date of the research were eligible to be included in the study, regardless of sentence length or the nature of offending. Participants were advised of the study and gave informed consent via their personal officer, who utilised standardised information and consent forms. For practical reasons a purposive sample of those willing and able to participate on that date was sought, and 14 young men chose to participate, representing almost one-quarter of the YOl's under 18 population on that date. All participants were aged 16 or 17 , three were on remand (as yet untried) and 11 were serving a sentence. In 
terms of the sample, it is acknowledged that this is a small-scale study and that, by using a selfselecting process, participants were limited to only those who volunteered to participate.

A focus group methodology was adopted in order to provide insight into how young people probed, challenged and responded to each other's views and also to enable a narrative to be developed between group members about their individual and collective journeys to prison (Bryman, 2004). A topic guide was developed to explore the research questions including: the young people's perspectives on, and experiences of, the CHS, adult court, community orders, secure care, and custody, as well as their views on how systems could be changed to meet young people's needs and improve outcomes. 12 young males participated across three focus groups, each containing between three and five participants. Three researchers were present during each focus group two of whom facilitated discussions while the other took notes. Two participants requested a one-to-one interview, with the same topic guide used for each focus group and interview.

With the consent of participants, each focus group was audio-recorded and partially transcribed, with each individual interview recorded via hand-written notes. A thematic approach to analysis was utilised, to focus on what participants were recounting about their experiences. While initial coding was guided by the research questions, other themes were allowed to emerge from the data. Initial coding was undertaken manually by one of the researchers, and independently double-coded by a second researcher for quality assurance, with these codes sense checked by the second author. Themes were then reviewed across two coding cycles. 


\section{Findings: A Journey Through Justice}

On analysing the data, the themes have been aligned to the chronological journey that young people have travelled on through the justice system via the CHS, adult court, community orders, secure care and custody; as well as the adversity experienced by young people prior to this journey commencing. All names have been changed.

\section{The Children's Hearings System}

The WSA advocates that where young people cannot be diverted from the criminal justice system, the first formal system they should enter is the Children's Hearings System, and 11 respondents reported having such previous involvement due to their offending. Participants described a childfriendly system, where they felt able to contribute by explaining their perspective and progress made and that in decision-making, panel members took a balanced approach, recognising both the positives and strengths of a young person and their situation and concerns. Young people's views varied about whether the CHS was harsh enough to serve as an effective deterrent or to learn from and create behaviour change, and their stance and experiences resulted in a differential impact when the protection of the CHS was removed:

When I was 16 , I thought I was still a wee boy...I got caught with two knifes when I was under 16 and one knife when I was 16 . When I was 15 you get taken to the police station, they phone your da and coz you're on a supervision order you get took back to the house. Then when I was 16 I got caught with one....and obviously I got took to Court for it (Callum)

In spite of legislative provisions enabling children to remain in this system until their 18th birthday and to provide advice to courts, no participants were still involved with the CHS. Over half of 
respondents commented that their Compulsory Supervision Order (CSO) had been terminated just prior to, or following, their 16th birthday. Research participants were often able to remember that this was "two days before", "five days after", "a week after my 16th birthday", and that in many instances offence cases were still outstanding or a serious offence was committed very quickly after this order being terminated. All respondents deemed the termination of their CSO to be a negative experience, with one child adamant that this should be the key finding from the research:

I think you shouldn't be allowed (to be) took off your CSO until you are 18 years of age unless you are doing really well...until you have completely and utterly changed, got an apprenticeship or something....and not like doing well for a month, it should be for at least a year... and you should be able to get put back on it (Alex)

Three participants specifically stated they believed the CHS could have managed their offences and the 'danger' they presented which had led to their current detention in custody.

The adult court

The WSA states that where prosecution in court cannot be avoided then in practice young people's engagement with the court system should be facilitated and enhanced support should be received. By virtue of their position in custody, all of the young people in the study had experience of the adult court and this was frequently described as a harsh experience, which was difficult to participate in and to understand:

I was in court the day after my 16th birthday and didn't know what was happening...I just didn't have a clue (Greg) 
Respondents recounted the difficulties experienced in attending what were often multiple court appearances for any one case and of delays in the court process. The implications that this could have on a young person's ability to access opportunities were significant:

When I was out I had got a house, a job, a bird [girlfriend] and a dog. Then eventually you go to court, get the jail and lose it all. The same you could keep your head down all the way through [your sentence] and it comes to tag date you don't get it because of outstanding cases (Kyle)

Over a quarter of respondents commented that the decision being made by the Sheriff/Judge was focused heavily on the negatives for that child, such as past behaviours and previous placements in secure care or custody, without reference to progress that may have been made:

The children's panel...gave me the opportunity for a new start but now you go to Court and because it's just bad stuff [the judge] just bangs you up (Kyle)

I got recalled but l'd done courses, had an apprenticeship, never missed meetings with my social worker.... My lawyer told the judge but he didn't take it into consideration (Oscar)

Respondents reported this could result in inconsistency in decision-making and sentencing, which they reported compounded their lack of understanding of the system.

Community Orders 
The WSA advocates that young people should be supported in their community wherever possible and when a young person appears at court alternatives to secure care and custody should be considered, with almost all of the young men having previously experienced some form of community-based measure via the adult court. The range and number of measures that had been utilised was vast, with significant issues reported in complying with such measures. 10 participants reported having been subject to bail conditions, the majority of whom stated they had breached these. Only a third described workers who supported them to adhere to such conditions. Two respondents advised they were no longer given bail as they had failed to comply so many times. Four of the young people stated they had previously been subject to a Community Payback Order (CPO), although again compliance with such orders and their conditions was reported to vary:

I had six chances for my CPO but kept patching them for supervision and unpaid hours. I never went so ended up back at court (Brian)

Nine respondents had previously been made subject to curfews, with many stating this included electronic monitoring and two specifically commenting that compliance had been short-lived:

I cut my tag off five days later (Kyle)

I lasted one day on the tag and then went on the run for a month (Ross)

A number of the participants reported issues with the timing of curfews, with only one stating he had managed to extend this to enable him to attend pro-social activities. Instead more frequently cited issues included timings constraining the ability to work and having different requirements of 
different orders, including different times for different curfews, often resulting in multiple breaches in any one incident.

These experiences lead a number of respondents to conclude that community orders were impossible to comply with:

It's just not realistic (Kyle)

I know if I'm out there I'll breach it (Brian)

Those participants who had not previously been subject to such orders stated they would prefer such measures and would comply with the conditions, but added the caveats that this would depend on curfew times and could be impacted on by issues in other areas of their lives, such as substance misuse:

I would rather be outside. I don't like being in here. I would accept the tag and comply with conditions, provided the curfew times were ok, and would stay out of trouble so I didn't come back here (Gary)

\section{Secure care}

Where young people's needs and risks cannot be managed and addressed in the community, the WSA states that secure care should be utilised rather than custody, yet less than half of the respondents reported having previously been in secure care due to their offending. Of the young people who had experience of secure care, the majority reflected positively and spoke fondly about the environment provided and relationships with, and supports from, staff: 
It's actually like being locked in your home... [the staff] treat you like you're their bairn [child] ...l'd go back in no time (Oscar)

Respondents advised that although secure care is a still a locked building and offers similar programmes to YOls, that they would prefer such a placement rather than custody. In addition to the above, young people cited increased freedoms and material provisions, and better contact and links with family, education provision and preparation for release as reasons for this. Two young people specifically stated that there should be more opportunities to return to secure care:

Secure is more likely to help me if I was in there for a long period of time. I've been in and out, in and out of prison...This place doesn't help me. l'd be better in secure (Alex)

Custody

Regrettably, however for many of the young people this was not their first experience of detention in a YOI, with nine participants having experienced a previous period on remand and two young people reported that this was their fourth time in custody. Respondents varied markedly in their views on custody, with a number of young people reflecting that removal from their circumstances outside custody prevented the committal of further and more serious offences and/or serious harm coming to the young person, either through their own behaviours or that of others. By contrast, many other young people were less positive about their experience of prison:

It sends folk insane (Ross)

They tell you when you can shower, speak to your family, when to eat (Ethan) 
Young people reported a wide range of services were available in custody such as youth work, groupwork, addictions support, employability services, social work, and support from third sector agencies. However, the accessibility of such services was reported to be constrained due to the awareness of services, remand status, staffing capacity to deliver services, and it being the decision of prison staff as to whether the young person could participate.

Two young people specifically stated that they believed no one under 18 should be in custody, with three respondents adding that it was particularly obvious to them that many young people should not be in prison:

A wee boy tried to kill himself the other day... He [judge] sent him here for seven days when he should be in secure. He's just a wee boy not cut out for prison (Oscar)

However, over a third of respondents stated there was little that others could do to reduce the YOI population, at times appearing almost hopeless that this was their fate:

It's up to the person. If they want to do the same thing and come back in they will keep doing it (Steve)

I would say more chances, but l've had all the chances in the world (Brian)

The journey's point of origin: childhood adversity and exclusion

While the above section has referred to young people's journeys through the justice system itself, in reality these journeys started long before any direct contact with justice system, originating in a childhood steeped in adversity. 11 respondents reported a history of social work involvement, for many dating back to their early years. Nearly all of the young people interviewed reported 
multiple experiences of loss; bereavement; abuse; trauma; family breakdown; parental ill health; parental inability to cope; homelessness; mental health difficulties; substance misuse; and sibling involvement in offending. Eight young people reported that they had been removed from their parent's care as a result of the above issues. Moreover, over half of those interviewed appeared to display comprehension and understanding difficulties, and speech, language and communication needs, in some cases at a level that the researchers deemed to be substantial.

While school may have provided a safe, stable, nurturing environment for these young people, by contrast, the majority of participants described experiencing disrupted education, movements between schools, truanting and lack of support. These young people had been excluded from school which they linked, along with inadequate alternative education provision, to their offending, citing the subsequent loss of opportunities, education and qualifications, as well as the unstructured use of time, as key issues:

After I got excluded from school, I started robbing houses, stealing cars, drinking every day, smashing stuff up (Steve)

As a result, over half of respondents spoke about the role of schools in keeping children in education and reducing the use of school exclusion as a means of preventing offending.

Furthermore, respondents advised there was a lack of available opportunities in the community, or at least awareness of these opportunities, to support children experiencing adversity and as a diversion from offending. Respondents deemed the availability, accessibility and awareness of leisure activities, apprenticeships or employment, accommodation, addictions support and offence focused work in the community was important in preventing and reducing offending and that young people should be involved in the development of these opportunities: 
You get opportunities in jail, like doing the Construction Skills Certification Scheme card, Duke of Edinburgh...outside you don't know where to go and access that stuff (Brian)

\section{Discussion}

The lived experiences of the young people in this research suggests that the espoused policy intentions of the WSA are the right ones, but are only partly being achieved in practice. It is positive that on their journey through the youth and criminal justice system, many respondents had experience of the more age-appropriate Children's Hearings System, the number and range of community orders experienced via the adult court were vast, and almost half had previously been placed in secure care. However, while it is difficult without full case information to comment on the rationale behind the decisions made in respect of individual respondents, this research has identified a number of areas where the consistent implementation of the WSA appears to be more problematic. These include the lack of understanding, information, participation and support reported by many respondents; the failure to maximise the use of the $\mathrm{CHS}$, particularly through the termination of orders, rather than the adult court system; and the use of custody rather than secure care, each of which has significant implications and warrants discussion. While it is acknowledged the implementation of policy into practice is inherently difficult, a number of barriers are identifiable, along with suggestions for change.

The gap between the espoused intention of the WSA that all young people should be included, informed and supported through the youth and criminal justice system, and the lived experienced of the young people in this research is particularly clear (Scottish Government, 2011d). Regardless of where in the system they found themselves, young people described a lack of information or, where information was received, they advised this was not always readily available 
or understandable, explained or helpful, at times relying on informal information from other people who they met during, or had been through, the process:

No-one tells you anything, you just need to find out yourself really (Ethan)

A similar picture was reported in lack of support being made available to young people to navigate this journey. This gap was most striking in the difficulties young people reported in understanding, engaging and participating in the adult court process, echoing the findings of Smith et al. (2014) and Cox (2013). This has crucial implications in respect of perceptions of procedural fairness, key components of which are individuals having the opportunity to be heard; feeling they have been respected; and understanding the decision-making processes, deeming that decisions have been made in a trustworthy and unbiased manner, and the requirements and expectations on them of such decisions (Bowen and Whitehead, 2016). Procedural fairness matters as research has shown when people feel they have been treated fairly, they are more likely to accept that the courts have a moral right to make decisions and subsequently to comply with such decisions, with research by Murphy (2015) finding this has greater importance for young people than for adults. Moreover, the implications in respect of young people's right to participate in decisions that affect them as enshrined in domestic legislation and the UNCRC are clear. Possible barriers to the implementation of this area of the WSA include that the information and support being made is available is insufficient to address the complexity and level of need presented by young people involved in offending behaviour, with this study echoing previous research in identifying the high prevalence of adversity, early system involvement, care history, and comprehension and understanding difficulties and speech, language and communication needs in the sample (Vaswani, 2014; Murray, 2012; Holligan, 2015; Broderick and Carnie, 2016; Smith et al., 2014; Chitsabesan et al., 2014). It may also be that such support is not being provided, with WSA a 
policy rather than a legislative requirement and Murray et al. (2015) highlighting buy-in to WSA policy and practice cannot be assumed and funding and the availability of resources is a concern. To support implementation, it is important that creative resources and methods to support young people's understanding of these systems and processes are developed, as also concluded by Smith et al. (2014). Moreover, this requires investment in developing, supporting, and sustaining the knowledge, understanding and skills of the workforce to ensure they are able to communicate to young people in accurate, accessible and meaningful ways, information about the systems they are involved in. It is also necessary to ensure that tailored, wide-ranging, individualised support that is proportionate to the level of need and risk presented is available to all young people on this journey, and the provision of such support is monitored on a multi-agency basis (Smith et al., 2014; Scottish Government, 2015a).

The failure to maximise the potential of the CHS, deemed by the young people in this research to be a much more positive, inclusive and understandable child-friendly system, particularly regarding the continuation of CSOs, is another critical finding. This has significant implications in terms of compliance with UNCRC and the right of children to be dealt with within the juvenile justice system and the ability to be retained within age appropriate processes and facilities, namely the CHS and secure care (Lightowler et al., 2014). Longer-term implications are also evident, including in respect of the differential arrangements for the disclosure of criminal convictions dependent on the disposal received, under the Rehabilitation of Offenders Act 1974, and in accessing aftercare support entitlements for care leavers, which are only available if the young person was "looked after", which can include being subject to a CSO through the CHS, on or after their 16th birthday. This issue highlights the disconnection between the intentions of the WSA policy and the legislative framework within which practical implementation takes place. In Scotland, the legislative definition of a child is inconsistent, dependent on which piece of 
legislation is being utilised (Dyer, 2016). We would therefore echo Dyer (2016) in concluding that if there is real commitment to addressing this issue, legislative change to define all under young people aged under 18 as children, to enable children to remain within the $\mathrm{CHS}$ until their 18th year, and changing the presumption that in all but the most serious of cases (solemn cases) under $18 \mathrm{~s}$ are dealt with through the $\mathrm{CHS}$ or through diversion from prosecution in jointly reported cases is required. Moreover, given that efforts to effect practice change have thus far had limited impact, further research, monitoring and guidance regarding 16/17 year olds in the CHS would be useful (Association of Directors of Social Work, 2011; Scottish Government, 2010).

Until this is achieved, young people will continue to be dealt with in the adult court, with further gaps between the policy intention of the WSA and practice evident in respect of young people's lack of support, understanding of the process, delays in proceedings and the rolling up of outstanding charges at court, the implications of which are as detailed above (Scottish Government, 2011b; Dyer, 2016). Addressing these issues in practice will require a multi-agency response with partnership working having been identified as key to the WSA, which is crucial if we are to improve on the experiences of our young people in court (Murray et al., 2015; Scottish Government, 2011b). In respect of the available disposals through court, while it is positive that many of the young people had experienced community orders, the difficulties in complying with such disposals and their ingrained sense of hopelessness at the chances of successful completion is important and consistent with other research findings (Scottish Government, 2011a; Bateman, 2011; Smith et al., 2014). This must be addressed as the costs of non-compliance are significant, as illustrated by Bateman (2011) in the link between non-compliance and entrance to custody, especially for short-term sentences, which are recognised as particularly ineffective (Bateman, 2016). To do so, adult court community orders should only be utilised where absolutely necessary, and in such instances should be accompanied with full explanations of the 
requirements of such orders and the costs of non-compliance, taking into account our findings on the high levels of need presented (Scottish Government, 2011b). Moreover, in determining the conditions and expectations of such orders, individual consideration should be taken of the child's age, developmental capacities and likely limited knowledge and experience of measures of this nature; potential fears and hopelessness about successfully completing orders; and how the barriers to successful compliance can be reduced and what support may be required (Smith et al., 2014; Cox, 2013). Further research into the effectiveness of such orders, and critically what can help to make them more effective, would be beneficial and support confidence in such approaches (Scottish Government, 2011c). Yet this research suggests that wider improvements to the court process for young people could be made, such as in incorporating the benefits cited by young people of the CHS to make courts more "child-friendly", or developing youth hearings or problem-solving courts for young people, although this would need to be informed by full consideration of what we know from the evidence on working with young offenders (Bowen and Whitehead, 2016; McLeish, 2008).

The unique findings from this research in young people's experience of both secure care and custody support the conclusions of the UNCRC that removal from the community should be the last resort and where necessary should be in a child-care establishment that promotes wellbeing and longer-term development (Harris et al., 2016). It has however highlighted issues in implementing the WSA stated preference of secure care rather than YOIs. Again this is likely to be influenced by the disconnect between policy, legislation and practice, with legally young people only able to be placed in secure care if they are subject to measures via the $\mathrm{CHS}$ at the point of sentence and financially, in respect of remand cases, the Scottish Government fund YOI placements but not secure care, with secure placements instead being the responsibility of the local authority (Lightowler et al., 2014; Murray et al., 2015). This may also be impacted on by the 
limited research on outcomes and therefore questionable effectiveness of such facilities, with almost half of the young people in this study having had previous experience of secure care, but likewise we know the use of the alternative (YOI) is not driven by evidence of effectiveness (Bateman, 2016; Armstrong and Weaver, 2013). Again, if the implementation of WSA is to be supported, we need to remove such barriers to the use of these age-appropriate facilities, which the legislative change proposed above would support, and reflect further as to how children can be enabled to return to secure care (Lightowler et al., 2014). Implementation may also be supported with further research into short and long-term outcomes for young people in secure care and addressing the calls for action made in the recent review of secure care (Gough, 2016; Moodie, 2015). There is however a wider issue to be addressed which is consideration of the threshold for a custodial sentence, what its purpose is, and what benefits it provides beyond what can be offered in the community, as well as to enable legislative reform (Bateman, 2016).

Arguably implementation of the WSA is further complicated because change and support is needed earlier in the system, prior to contact with justice services. In this research the majority of respondents were known to social work, the $\mathrm{CHS}$ and care experienced, often having been known to services from a young age, underlining the need for preventative and early intervention support as is advocated under Scotland's approach to improving outcomes for children Getting It Right for Every Child (Scottish Government, 2014b). Moreover, this research has echoed the findings of previous studies on the impact of school exclusion and the link with offending behaviour, supporting the need for strategic focus on this area under Government policy (McAra and McVie, 2010; Smith et al., 2014; Holligan, 2015; Scottish Government, 2015a). Thus far however, efforts have had far less impact on pupils with additional support needs and those who live in the areas of greatest deprivation, factors again which are often prevalent in the experiences of young people involved in offending (Scottish Government, 2015c). Continued efforts are needed to ensure that 
support is available to the most challenging and disengaged young people (Scottish Government, 2015c). Likewise, this research has raised questions about whether there is more the care system can do in preventing offending, which is particularly timely given that Scotland is currently undertaking a root and branch review of the care system, and the role of community-based supports and services to ensure young people do not need to enter custody as a means of addressing needs and accessing services (Tata, 2016; Scottish Government, 2017a). This is essential if we are to address the pervasive sense of hopelessness in young people who believe that ending up in custody is inevitable rather than a tragic failure of the system.

\section{Acknowledgments}

The authors thank the Scottish Prison Service for access to undertake this study and the 14 young people who participated. Thanks also to Pamela Morrison and Donna McEwan for supporting the facilitation of the focus groups and Claire Lightowler and University of Strathclyde staff for their support.

\section{Funding}

This research received no specific grant from any funding agency in the public, commercial, or not-for-profit sectors.

\section{References}


Allen G and Watson C. (2017) UK Prison Population Statistics. London: House of Commons Library.

Armstrong S and Weaver B. (2013) Persistent punishment: User views of short prison sentences. The Howard Journal of Criminal Justice 52: 285-305.

Association of Directors of Social Work. (2011) Young People aged between 15 and 17 in the Children's Hearing System. Edinburgh: Association of Directors of Social Work.

Barry M. (2016) On the cusp of recognition: Using critical theory to promote desistance among young offenders. Theoretical Criminology 20: 91-106.

Bateman T. (2011) 'We now breach more kids in a week than we used to in a whole year': the punitive turn, enforcement and custody. Youth Justice 11: 115-133.

Bateman T. (2016) The State of Youth Custody. London: National Association of Youth Justice.

Bowen P and Whitehead S. (2016) Problem-solving courts: An evidence review. London: Centre for Justice Innovation.

Broderick R and Carnie J. (2016) Young People in Custody 2015. Edinburgh: Scottish Prison Service.

Bryman A. (2004) Social research methods, Oxford: Oxford University Press.

Chitsabesan P, Lennox C, Theodosiou L, et al. (2014) The development of the comprehensive health assessment tool for young offenders within the secure estate. The Journal of Forensic Psychiatry \& Psychology 25: 1-25.

Convery U. (2010) Researching Young People's Experiences of Detention. Proceedings of the 20th Anniversary Conference the IUC Dubrovnik School of Social Work Theory and Practice, June 28-July 4, 2009. Inter-university centre Dubrovnik.

Cox A. (2013) New visions of social control? Young people's perceptions of community penalties. Journal of Youth Studies 16: 135-150.

Davis C, Bahr S and Ward C. (2013) The process of offender reintegration: Perceptions of what helps prisoners reenter society. Criminology \& Criminal Justice 13: 446-469.

Deuchar R, Mørck L, Matemba Y, et al. (2016) 'It's as if you're not in the Jail, as if you're not a Prisoner': Young Male Offenders' Experiences of Incarceration, Prison Chaplaincy, Religion and Spirituality in Scotland and Denmark. The Howard Journal of Crime and Justice 55: 131-150.

Dyer F. (2016) Young People at Court in Scotland. Glasgow: CYCJ.

Gough A. (2016) Secure Care in Scotland: Looking Ahead. Glasgow: CYCJ.

Hamilton C, Fitzgibbon W and Carr N. (2016) Punishment, youth justice and cultural contingency: Towards a balanced approach. Youth Justice 16: 226-245.

Hampson KS. (2016) From the Mouths of Dragons: How Does the Resettlement of Young People from North Wales Measure Up... In Their Own Words? Youth Justice 16: 246-262.

Harris J, Millership L, Moodie N, et al. (2016) State of Children's Rights in Scotland. Edinburgh: Together.

Holligan C. (2015) "The Cake and Custard is Good!" A Qualitative Study of Teenage Childrens' Experience of being in Prison. Children \& Society 29: 366-376. 
Lightowler C, Orr D and Vaswani N. (2014) Youth Justice in Scotland: Fixed in the Past or Fit for the Future? Glasgow: CYCJ.

McAra L. (2008) Crime, criminology and criminal justice in Scotland. European Journal of Criminology 5: 481-504.

McAra L and McVie S. (2010) Youth crime and justice: Key messages from the Edinburgh Study of Youth Transitions and Crime. Criminology and Criminal Justice 10: 179-209.

McLeish H. (2008) Scotland's Choice: Report of the Scottish Prisons Commission. Edinburgh: Scottish Government.

Moodie K. (2015) Secure Care in Scotland, a Scoping Study: Developing the measurement of outcomes and sharing good practice. Glasgow: CYCJ.

Murphy K. (2015) Does procedural justice matter to youth? Comparing adults' and youths' willingness to collaborate with police. Policing and Society 25: 53-76.

Murray K, McGuinness P, Burman M, et al. (2015) Evaluation of the whole system approach to young people who offend in Scotland. Edinburgh: Scottish Government

Murray R. (2012) Children and Young People in Custody 2011-12: An analysis of the experiences of 15-18 year olds in prison, London: Stationery Office.

National Institute of Mental Health. (2011) The Teen Brain: Still Under Construction. London: Department of Health and Human Science.

Nolan D. (2017) The story behind the figures. Raising Youth Justice. Glasgow: CYCJ.

Phoenix J and Kelly L. (2013) 'You Have To Do It For Yourself' Responsibilization in Youth Justice and Young People's Situated Knowledge of Youth Justice Practice. British Journal of Criminology 53: 419-437.

Pitts J. (2005) The recent history of youth justice in England and Wales. In: Bateman T and Pitts J (eds) The RHP Companion to Youth Justice. Lyme Regis: Russell House Publishing, 2-11.

Rutherford A. (2002) Growing out of crime: The new era, Winchester: Waterside Press.

Scottish Government. (2010) National Outcomes and Standards for Social Work Services in the Criminal Justice System: Criminal Justice Social Work Reports and Court-based Services Practice Guidance. Edinburgh: Scottish Government.

Scottish Government. (2011a) Alternatives to Secure Care and Custody Guidance. Edinburgh: Scottish Government.

Scottish Government. (2011b) Assisting Young People aged 16-17 in Court. Edinburgh: Scottish Government

Scottish Government. (2011c) Diversion from Prosecution Toolkit-Diverting Young People from Prosecution, Young People Who Offend: Managing High Risk and Transitions. Edinburgh: Scottish Government.

Scottish Government. (2011d) Reintegration and Transitions - Guidance for Local Authorities, Community Planning Partnerships and Service Providers. Edinburgh: Scottish Government.

Scottish Government. (2014a) Framework for Risk Assessment Management and Evaluation (FRAME) for Local Authorities and partners For Children and Young People under 18. Edinburgh: Scottish Government. 
Scottish Government. (2014b) A Guide to getting it Right for Every Child. Edinburgh: Scottish Government

Scottish Government. (2015a) Preventing Offending Getting it right for children and young people. Edinburgh: Scottish Government.

Scottish Government. (2015b) Prison statistics and population projections Scotland: 2013-14. Edinburgh: Scottish Government

Scottish Government. (2015c) Summary statistics for schools in Scotland. Edinburgh: Scottish Government.

Scottish Government. (2017a) Independent review into care system. Edinburgh: Scottish Government

Scottish Government. (2017b) Youth Justice Strategy 'Preventing Offending: Getting it right for children and young people' - Progress Report. Edinburgh: Scottish Government.

Smith S, Dyer F and Connolly G. (2014) Young Men in Custody: A report on the pathways into and out of prison of young men aged 16 and 17. Glasgow: CYCJ.

Tata C. (2016) How can prison sentencing be reduced in Scotland? Scottish Justice Matters 4: 2325.

Terry D and Abrams LS. (2015) Dangers, diversions, and decisions: the process of criminal desistance among formerly incarcerated young men. International journal of offender therapy and comparative criminology: 1-24.

Vaswani N. (2014) The ripples of death: exploring the bereavement experiences and mental health of young men in custody. The Howard Journal of Criminal Justice 53: 341-359.

\section{Author biographies and contact details}

Deborah Nolan, Practice Development Advisor at the Centre for Youth and Criminal Justice, has a Master of arts and of social work and research interests in reintegration and transitions for young people in secure care and custody and the criminalisation of looked after children.

Centre for Youth and Criminal Justice, University of Strathclyde, Lord Hope Building, 141 St. James Road, Glasgow, G4 OLT 
Email: deborah.nolan@strath.ac.uk

Tel: 01414448622

Fiona Dyer, Deputy Director at the Centre for Youth and Criminal Justice, has a Masters in social work and $\mathrm{MsC}$ in advanced criminal justice studies and has previously completed research on young people in custody.

Centre for Youth and Criminal Justice, University of Strathclyde, Lord Hope Building, 141 St. James Road, Glasgow, G4 OLT

Email: fiona.dyer@strath.ac.uk

Tel: 01414448622

Nina Vaswani, Research Fellow and Research Lead at the Centre for Youth and Criminal Justice is interested in the adverse childhood experiences of young people on their journey to custody, and the impact of custody on young people.

Centre for Youth and Criminal Justice, University of Strathclyde, Lord Hope Building, 141 St. James Road, Glasgow, G4 OLT

Email: nina.vaswani@strath.ac.uk

Tel: 01414448622 